\title{
Democratizing Higher Education: Exploring MOOC Use Among Those Who Cannot Afford a Formal Education
}
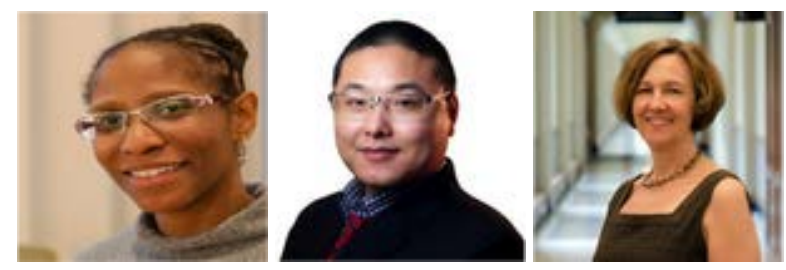

Tawanna Dillahunt ${ }^{1}$, Zengguang Wang ${ }^{1}, 2$, and Stephanie D. Teasley ${ }^{1}$

1University of Michigan, USA, ${ }^{2}$ Peking University, China

\section{Abstract}

Massive open online courses ("MOOCs") provide free access to higher education for anyone with Internet access. MOOCs are considered a means for democratizing education. These courses will hopefully provide an opportunity for individuals to learn from the best educators in the world, as well as help expand their personal networks, and facilitate their career development. However, research thus far shows that the majority of people taking advantage of these courses are already employed, have postsecondary degrees, and have encountered few barriers related to the affordability of higher education. Little is known about MOOC learners with financial constraints and who do not fit the typical profile of MOOC learners. This paper presents the results of the analysis of data from six Coursera courses offered by the University of Michigan from fall 2012 through winter 2013. In this analysis learners who self-identified as being unable to afford to pursue a formal education (the target group) were contrasted to other learners (the comparison group) in terms of demographics, motivations, course enrollment, engagement and performance. Learners in the target group were primarily male and over 25 years old. A statistically significant portion of the target group held less than a 4-year college degree than the comparison group. Target learners were also significantly underrepresented in the enrollment of the courses examined here. Although the comparison group had a significantly higher completion rate overall than the target group, the target group had a statistically significant higher rate of completing courses with certificates of distinction. This article provides a discussion of these results and suggests how MOOCs could be adapted to better address the needs of learners who feel financially unable to pursue a more traditional path to a post-secondary education.

Keywords: Massive open online courses; education; online learning; affordability 


\section{Introduction}

Massive open online courses (MOOCs) are seen as an opportunity to gain access to education and professional development, and to develop new skills to prepare for highpaying jobs (Pappano, 2012). Recent articles on MOOCs in both the scholarly literature and the popular press emphasize the fact that hundreds of thousands of people around the world now have access to courses offered by elite universities (Lewin, 2012). Information and communication technologies have increased opportunities for higher education, though the key beneficiaries are individuals from affluent families from the Western Province (Liyanagunawardena, 2012). In addition, research thus far consistently shows that the people taking advantage of MOOCs are already employed, young, well educated, predominantly male, from developed countries, have higher levels of formal education, and are unlikely to encounter barriers related to the affordability of higher education (Christensen, Steinmetz, Alcorn, Bennett, Woods, Emanuel, 2013). In short, the individuals expected to benefit most from MOOCs are inadequately represented among the early adopters of this new form of education (Christensen et al., 2013). Although MOOCs are seen as one possible path toward upward mobility, few studies have examined whether and how the populations with the most to gain leverage these resources. Therefore the goal of this study was to address the following question to complement prior research: How do the demographics, enrollment, personal motivations, performance and engagement of learners unable to afford a formal education compare or contrast to learners who do not report being motivated by financial constraints?

This paper provides the results of a comparison between MOOC learners who selfidentified as being unable to afford to pursue a formal education (the target group) with other learners (the comparison group), looking specifically at demographic data and motivations across 11 Coursera offerings from fall 2012 to winter 2013. The results detailed here contribute a better understanding of an understudied and underrepresented group. The aim is to determine how MOOCs might better serve those who feel financially unable to pursue a more traditional path to post-secondary education studies.

\section{Related Work}

Massive open online courses are considered a means for democratizing education (Lewin, 2012; Wulf, Brenner, Leimeister, 2014). MOOCs address an unlimited number of participants ("massive"); are offered free of charge or impose only low participation fees ("open"); are not dependent on location as they are available via the Internet ("online"); and the content consists of instructional lectures and assessment ("courses") (Wulf, Brenner, Leimeister, 2014; Clow, 2013; McAuley et al., 2010; Vardi, 2012). However, research shows that MOOCs are reaching a fairly homogeneous population 
and that those thought to benefit most from these courses are underrepresented in course enrollments (e.g., Christensen, Steinmetz, Alcorn, Bennett, Woods, \& Emanuel, 2014). Therefore, it is unclear how people who are financially constrained, who may be unemployed, and who have less formal education are taking advantage of these courses. The question of whether they can benefit from participating in this new educational context also remains open.

In a systematic review of 45 peer-reviewed papers in the MOOC-related literature published between 2008-2012, Liyanagunawardena, Adams, and Williams (2013) found that the majority of articles discussed MOOC challenges and trends. McAuley, Stewart, Siemens, and Cormier (2010) advocated for a clear research agenda to help evaluate both the feasibility and the potential of the MOOC model for opening up access to higher education and the circumstances in which MOOCs might achieve this potential. They identified several open questions and challenges, such as the role for MOOC accreditation, understanding depth versus breadth in MOOC participation, understanding the conditions in which MOOC participation can expand beyond those with broadband access and advanced social networking skills, and the viability of MOOCs from an economic perspective. Understanding how underrepresented learners compare to the majority of MOOC learners in terms of demographics, motivations, engagement and performance could help to evaluate the feasibility of the conditions by which MOOCs might achieve their potential for democratizing education.

Researchers from the University of Pennsylvania analyzed more than 400,000 surveys from individuals enrolled in 32 Coursera courses (Christensen, Steinmetz, Alcorn, Bennett, Woods, Emanuel, 2013). In these courses, 83\% of the registered learners had two-or four-year degrees, and of those, $44 \%$ had some graduate education. According to an analysis of 17 online courses offered on the edX platform, Ho et al. (2014) found that of those reporting, the most typical edX MOOC learners were males with bachelor's degrees who are 26 and older (31\% of learners). Learners reporting their gender as female represented $29 \%$. Learners enrolling in these MOOCs appeared to be diverse in terms of highest education achieved (33\% reported high school and lower), age (6.3\% reported being 50 or older) and $2.7 \%$ of the students had mailing or IP address from the least developed countries as listed on the United Nations (Ho, Reich, Nesterko, Seaton, Mullaney, Waldo \& Chang, 2014). The authors reported that despite the low percentages of learners from typically underserved populations, these courses were still reaching a large number of these learners and that the edX MOOCs were attracting diverse audiences.

MOOCs are still relatively new (Clow, 2013) and unexplored in the literature on distance education and online distance learning. Many research questions are still open in regard to the learning analytics on MOOCs and understanding trends such as the high drop rates (Clow, 2013). In particular, future research should further investigate the types of learners taking advantage of MOOCs and their motivations. The research discussed in this article provides an understanding of a population that has not yet been studied- 
learners who report being unable to afford a formal education. The data for this study comes from learners who registered in Coursera courses offered by the University of Michigan, a large midwestern university in the U.S. The goal of the research was to address the following research question: How do the demographics, enrollment, personal motivations, performance and participation of learners compare or contrast to learners who do not report being motivated by financial constraints? This article provides the results of this analysis, and suggests how MOOCs could be adapted to better meet the needs of this population. The results help to further develop hypotheses regarding the performance and demographics of these populations across multiple MOOC courses, platforms, and universities.

\section{Methodology}

As this study was exploratory in nature, statistical methods consisted of a series of comparative analyses between the target and the comparison group. These data were collected from the demographic surveys jointly administered by Coursera and the University of Michigan at the beginning of six courses (see Table 1). The surveys were voluntary and could be answered at any time during the course session. These surveys were designed to provide learner demographic information and their motivation for taking the MOOC (see Table 1, Question \#3 for a complete list of motivations, and note that learners could select more than one answer). Any learner who included the answer indicating that they were unable to afford a formal education were classified as the "target group" for analyses. The "comparison group" comprised of those learners who selected any of the reasons other than affordability for enrolling in the course. Although determining the target group on the basis of a single survey question does not reveal possible variability in what affordability means to respondents, affordability was the major factor identifying underrepresented learners in previous MOOC research.

Course enrollment, engagement, and performance data was available via the data provided by the MOOC platform. Course engagement data included whether learners accessed course material, watched videos and engaged in discussion forums. In terms of forum engagement, learners could engage in four distinct activities: view a forum, view a thread, up vote a thread or down vote threads. Forum posting data was not readily available and does not appear in this analysis. Course performance data is available through grades achieved in the course. There were two types of course completion certificates - a basic "certificate of completion" and a "certificate of completion with distinction." In general, earning a certificate required completion of the course with a minimum grade, or meeting a set of requirements set by each instructor; earning a certificate of distinction required passing with a higher grade threshold (which varied from course to course). Before discussing the results of the analysis, details of the course survey are presented next, as well as an overview of the courses analyzed. 
Table 1

Survey Questions Used in Analysis

1. What is your gender? (open ended)

2. What is your age? $\square$ Under 18

$\square$ 35-44

$\square$ I prefer not to answer

3. Which options best describe your motivations for taking this class? (please check all that apply)

\begin{tabular}{|c|c|c|}
\hline $\begin{array}{l}\square \text { Cannot afford to } \\
\text { pursue a formal } \\
\text { education }\end{array}$ & $\begin{array}{l}\square \text { Supplement other } \\
\text { college/ university courses }\end{array}$ & $\begin{array}{l}\square \text { Geographically isolated } \\
\text { from educational institutions }\end{array}$ \\
\hline $\begin{array}{l}\square \text { Extending current } \\
\text { knowledge of the } \\
\text { topic }\end{array}$ & $\square$ General interest in the topic & $\begin{array}{l}\square \text { Decide if I want to take } \\
\text { college/ university classes on } \\
\text { the topic }\end{array}$ \\
\hline $\begin{array}{l}\square \text { Professional } \\
\text { development }\end{array}$ & $\begin{array}{l}\square \text { Interest in how these } \\
\text { courses are taught }\end{array}$ & \\
\hline \multicolumn{3}{|c|}{ 4. What is your highest level of education? } \\
\hline $\begin{array}{l}\square \text { Some high } \\
\text { school }\end{array}$ & $\square$ High school & $\square$ Some college \\
\hline $\begin{array}{l}\square \text { Associate's } \\
\text { degree ( } 2 \text { year's of } \\
\text { college) }\end{array}$ & $\begin{array}{l}\square \text { Bachelor's degree (BA/BS 4- } \\
\text { year's of college) }\end{array}$ & $\square$ Master's degree \\
\hline \multicolumn{3}{|c|}{ 5. What is your current occupation? Select all that apply } \\
\hline $\begin{array}{l}\square \text { Student } \\
\square \text { Other }\end{array}$ & $\square$ Faculty & $\square$ Teacher \\
\hline
\end{tabular}

\section{Survey and Course Overview}

Survey responses were gathered from multiple offerings of six distinct courses offered in the fall of 2012 through the winter of 2013, for a total of 11 course offerings. These courses were 5 to 15 weeks long and taught by university professors at the University of Michigan. The advertised workload for the courses ranged from 4-12 hours per week. The courses were classified into three categories: 1) Humanities, 2) Economics and Finance, and 3) Technology. Specific course names are included in Table 2. 
Table 2

Summary of Courses Offered

\begin{tabular}{llc} 
Course Type & Course Names & Course \# \\
Humanities & Fantasy and Science Fiction & 1 \\
Economics and & Model Thinking & 2 \\
Finance & Intro to Finance & 3 \\
Technology & Internet, History, Technology and & 4 \\
& Security & 5 \\
& Social Network Analysis & 6 \\
\hline
\end{tabular}

\section{Results}

In total, 666,407 learners registered for the six courses and approximately $6.3 \%$ $(\mathrm{N}=42,097)$ took the demographic surveys. Note that not all of the questions were answered by every student thus the $n$ varies by item (see survey response rates in Table 3). Only 9.08\% $(\mathrm{N}=3,812)$ of those completing surveys represented the target population (i.e., stated that they were not able to afford a formal education).

Table 3

Number of Survey Participants and Response Rates for each Course by Term Offered

\begin{tabular}{|c|c|c|c|}
\hline \multirow[t]{2}{*}{ Course type } & \multirow[t]{2}{*}{ Course \# } & \multicolumn{2}{|c|}{ \#Participants } \\
\hline & & Fall 2012 & Winter 2013 \\
\hline Humanities & 1 & 37,118 (2.90\%) & 23,318 (.77\%) \\
\hline \multirow[t]{2}{*}{ Economics and Finance } & 2 & $102,802(2.47 \%)$ & $38,429(17.50 \%)$ \\
\hline & 3 & $125,332(5.42 \%)$ & $89,362(9.50 \%)$ \\
\hline \multirow[t]{3}{*}{ Technology } & 4 & 41,683 (10.94\%) & 34,218 (18.67\%) \\
\hline & 5 & $61,754(1.97 \%)$ & $35,363(10.29 \%)$ \\
\hline & 6 & $19,582(2.43 \%)$ & $* \mathrm{NA}$ \\
\hline
\end{tabular}

Note. *Survey responses were unavailable.

Table 3 shows that the courses with the highest survey response rates occurred in the winter of 2013. While the causes of these variations in response rates are unclear, factors such as the popularity of MOOCs in general or the commitment of learners after evaluating the courses the first time around may reflect response rates. 
The next section provides the results of the demographic survey, motivations for enrollment (e.g., other than an inability to afford a formal education), and course enrollment details. The section concludes with details about how the target population performed relative to the comparison group. Where applicable, statistically significant differences between the target and comparison groups are specified.

\section{Demographics}

Overall, 41,636 learners that responded to the question of gender and $68.65 \%$ $(\mathrm{N}=28,585)$ were male. Of the 41,734 learners that responded to the question of age, the largest age group taking courses was 25-34 (39.78\%, N=16,603), and the second largest age group was $18-24(22.67 \%, \mathrm{~N}=9,461)$. For the total number of learners responding to the survey, $99.68 \%(\mathrm{~N}=41,961)$ answered the question regarding their motivations for taking the course. Of these, approximately 9.08\% $(\mathrm{N}=3,812)$ were in the target population. The remaining $90.92 \%(\mathrm{~N}=38,149)$, those in the comparison group, did not select affordability as their motivation for taking the courses.

Tables 4-1 and 4-2 provide a breakdown of the gender and age of the target and comparison groups.

Table 4-1

Gender Breakdown for Learners in the Target vs. Comparison Groups

Target

(i.e., Cannot afford, $\mathrm{N}=3,762$ )

Gender Count Percentage

Male $\quad 2,467 \quad 65.58 \%$

Female $\quad 1,295 \quad 34.42 \%$
Comparison

(i.e., Other, $\mathrm{N}=37,788$ )

Gender Count Percentage

Male $\quad 26,053 \quad 68.95 \%$

Female $\quad 11,735 \quad 31.05 \%$

Table 4-2

Age Breakdown for Learners in the Target vs. Comparison Groups

Target

(i.e., Cannot afford, $\mathrm{N}=3,798$ )

Age Count Percentage

18-24 $764 \quad 20.12 \%$

$25-34 \quad 1,690 \quad 44.50 \%$
Comparison

(i.e., Other, $\mathrm{N}=37,855)$

Gender Count Percentage

Male $\quad 8,678 \quad 22.92 \%$

Female $\quad 14,883 \quad 39.32 \%$ 
The target and comparison groups are relatively the same in terms of gender and age. Learners in both groups were primarily male ( $70 \%$ ) and between $25-34$ years old. This finding is consistent with the age and gender demographics reported in prior research (Christensen, Steinmetz, Alcorn, Bennett, Woods, Emanuel, 2013).

Overall, 37,148 learners responded to the question of motivation and country of origin. Table 5 provides a summary of the country of origin of both groups.

Table 5

*Country of Origin, Count and Percentage of Enrollment for Learners in the Target vs. Comparison Groups

Target

(i.e., Cannot afford, N=3,191)

Country Count Percentage

US $\quad 1,065 \quad 33.38 \%$

IN $\quad 236 \quad 7.40 \%$

GB $\quad 154 \quad 4.83 \%$
Comparison

(i.e., Other, $\mathrm{N}=33,957)$

Country Count Percentage

US $\quad 9,615 \quad 28.32 \%$

IN $\quad 2659 \quad 7.83 \%$

BR $\quad 1,502 \quad 4.42 \%$

*Note that the survey asks for country of origin rather than the current country of residence.

The majority of learners in the target and comparison groups were from the United States, followed by India. Great Britain was third among the target group while Brazil was third among the comparison group. Consistent with prior research, the single largest group of learners is from the U.S., but there were also learners taking courses from developing regions (Ho, Reich, Nesterko, Seaton, Mullaney, Waldo, \& Chuang, 2014).

\section{Educational Achievement}

Overall, 41,709 participants responded to the survey question regarding their motivations for taking the course and their highest educational degrees achieved (Figure 1 questions 3 and 4). See Table 6 for details. 
Table 6

Degree Achievement for Learners in the Target and Comparison Groups

\begin{tabular}{lcc} 
Group & $\begin{array}{l}\text { Target } \\
\text { (i.e., Cannot afford, } \\
\text { N=3,790) }\end{array}$ & $\begin{array}{l}\text { Comparison } \\
\text { (i.e., Other, } \\
\text { N=37,919) }\end{array}$ \\
Some high school & 72 & 512 \\
& $12.33 \%$ & $87.67 \%$ \\
High school & 355 & 2,294 \\
& $13.40 \%$ & $86.60 \%$ \\
Some college & 593 & 2,742 \\
Associate's degree & $17.78 \%$ & $82.22 \%$ \\
(2 years of college) & 251 & 1,524 \\
Bachelor's degree & $14.14 \%$ & $85.86 \%$ \\
(BA/ BS, 4 years of & 1,519 & 13,931 \\
college) & $9.83 \%$ & $90.17 \%$ \\
Master's degree & 834 & 13,194 \\
& $5.95 \%$ & $94.05 \%$ \\
Professional degree & 85 & 1,354 \\
(MD, J D) & $5.91 \%$ & $94.09 \%$ \\
Doctoral degree & 81 & 2,368 \\
& $3.31 \%$ & $96.69 \%$ \\
\hline
\end{tabular}

As shown in Table 6, approximately one third $(33.63 \%, \mathrm{~N}=14,028)$ of all individuals responding to the survey reported that their highest degree achieved was a master's degree, and 37.04\% ( $\mathrm{N}=15,450)$ had a bachelor's degree. These results also show that a statistically significantly higher percentage of the target population reported having a bachelor's degree than those in the comparison group ( $40.08 \%$ vs. $36.74 \%, z=4.06, p<$. 01).

In addition, a larger majority of target learners had bachelor's degrees (40.08\% $\mathrm{N}=1,519)$ than master's degrees $(22.01 \% \mathrm{~N}=834)$, which is significantly different from the comparison group ( $36.74 \% \mathrm{~N}=13,931$ vs. $34.80 \% \mathrm{~N}=13,194$ respectively) ( $\mathrm{z}=52.18$ $\mathrm{p}<0.01$ ). In fact, learners in the comparison group had a statistically significant higher proportion of advanced degrees (e.g., master's degree and higher) than the target group ( $44.61 \%$ vs. $26.39 \%, z=21.61, p<0.01$ ), while a statistically significant portion of the target group had less than a four-year college degree in contrast to the comparison group (33.54\% vs. $18.65 \%$, $\mathrm{z}=21.84, \mathrm{p}<0.01)$. 


\section{Motivations}

Figure 1 shows a comparison of the reported motivations (excluding the ability to afford a formal education) for taking MOOCs between the target and comparison populations $(\mathrm{N}=42,097)$.

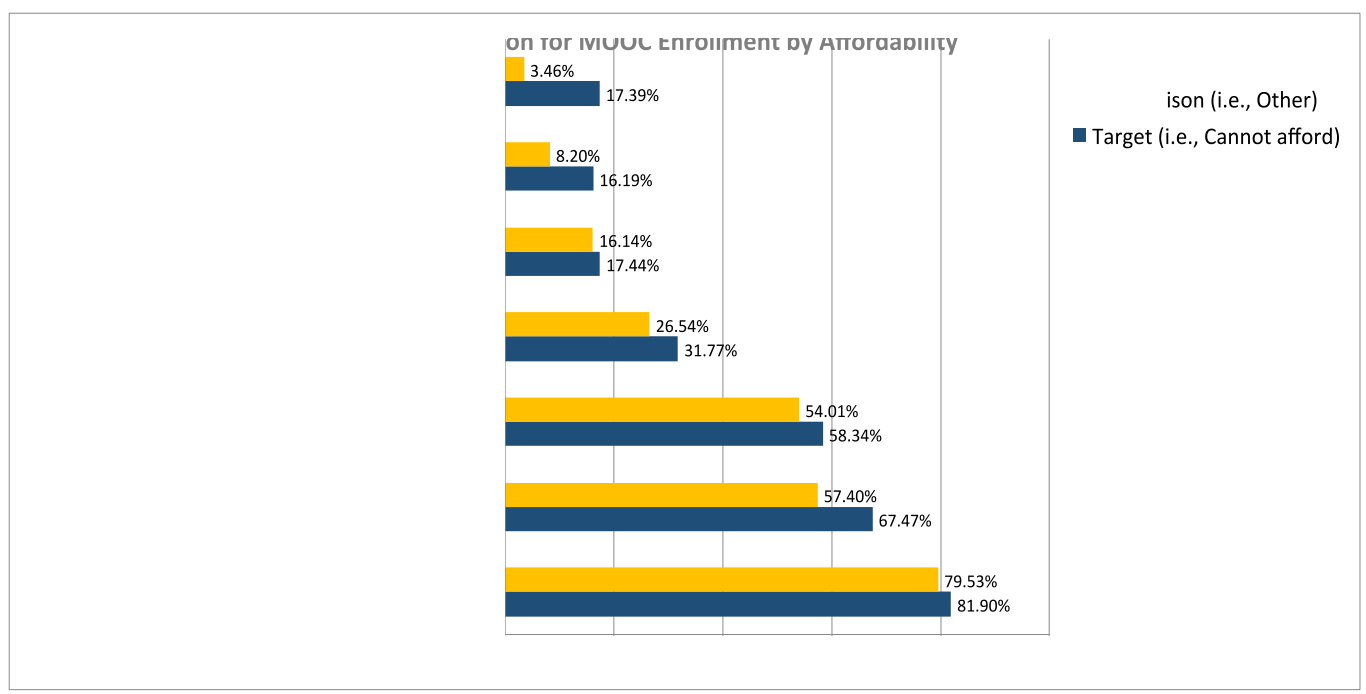

Figure 1. Additional motivations of learners based on affordability.

Given the large number of learners, all differences were statistically significant at the $\mathrm{p}<0.01$ level (except to supplement other college/ university classes/courses). The target learners, however, were five times more likely to indicate being motivated to take courses due to issues of geographic isolation than the comparison learners. The target learners were twice as likely to indicate being motivated to decide if they wanted to take college/ university classes on the topic.

\section{Course Enrollment}

Course enrollment data (Figure 2) was analyzed based on education level in addition to affordability to compensate for any barriers to entry in terms of course difficulty. 
All learners:
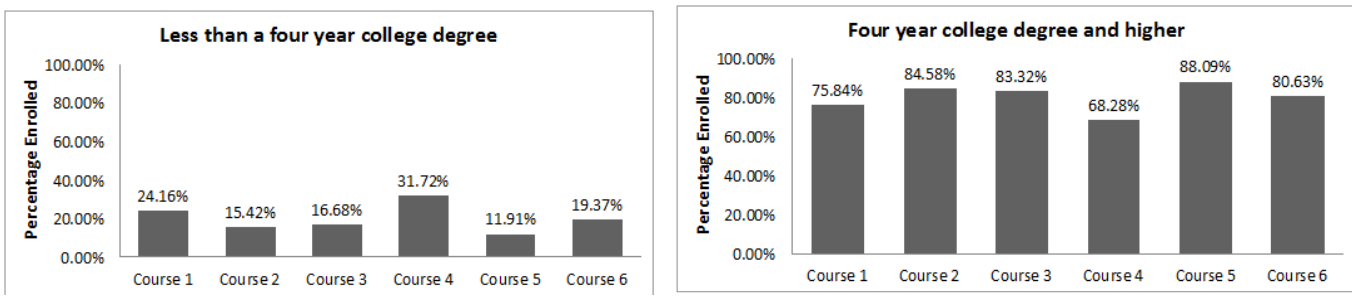

Target Learners:
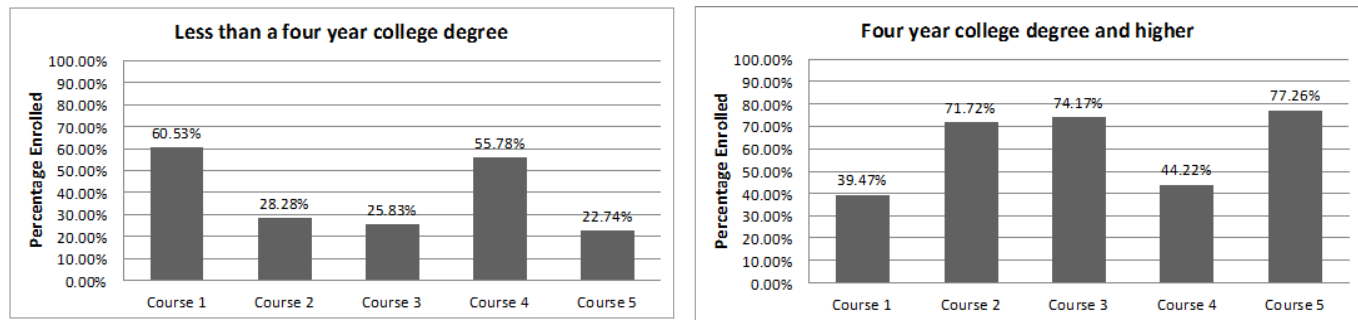

Comparison Learners:
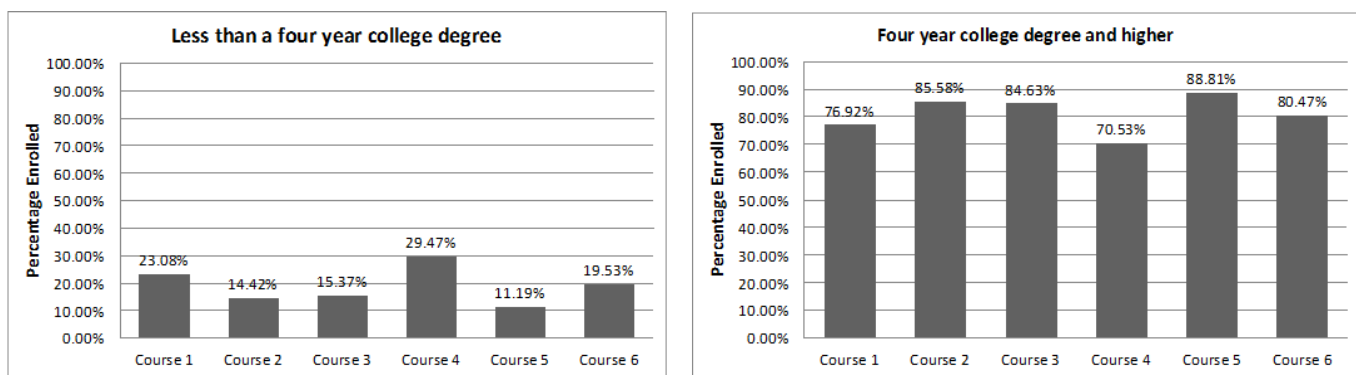

Figure 2. Percentage of course enrollment by degree achievement.

Note. Course 1: Fantasy and Science Fiction

Course 2: Model Thinking

Course 3: Introduction to Finance

Course 4: Internet, History, Technology and Security

Course 5: Social Network Analysis

Course 6: Securing Digital Democracy

Figure 2 shows that the two courses with the highest enrollment percentage for those with less than a 4-year degree across both target and comparison learners were Courses 4, which is a basic, technology-related course and 2 (Economics). By contrast, the 
highest percentage of enrollment for those with 4-year degrees and higher was Course 5, a more advanced technology course, followed by Courses 2 (Economics) and 3 (Finance).

Table 7 provides details regarding the actual number and percentage of the enrollment of each course per term offered. Note that none of the learners enrolled in the Humanities and Technology courses offered in the fall 2012 term reported an inability to afford a formal education (Table 7).

Table 7

Representation of Target and Comparison Groups by Course

\begin{tabular}{|c|c|c|c|c|c|}
\hline Course type & Term & $\begin{array}{l}\text { Target } \\
\text { learners }\end{array}$ & $\begin{array}{l}\text { Percentage } \\
\text { of target } \\
\text { enrolled }\end{array}$ & $\begin{array}{l}\text { Comparison } \\
\text { learners }\end{array}$ & $\begin{array}{l}\text { Percentage } \\
\text { of } \\
\text { comparison } \\
\text { enrolled }\end{array}$ \\
\hline \multirow[t]{2}{*}{ Humanities } & Fall 2012 & - & $0.00 \%$ & 3,607 & $100.00 \%$ \\
\hline & $\begin{array}{l}\text { Winter } \\
2013\end{array}$ & 688 & $9.99 \%$ & 6,199 & $90.01 \%$ \\
\hline \multirow[t]{2}{*}{$\begin{array}{l}\text { Economics } \\
\text { and Finance }\end{array}$} & Fall 2012 & 847 & $12.52 \%$ & 5,917 & $87.48 \%$ \\
\hline & $\begin{array}{l}\text { Winter } \\
2013\end{array}$ & 1,062 & $12.54 \%$ & 7,407 & $87.46 \%$ \\
\hline \multirow[t]{2}{*}{ Technology } & Fall 2012 & - & $0.00 \%$ & 6,239 & $100.00 \%$ \\
\hline & $\begin{array}{l}\text { Winter } \\
2013\end{array}$ & 1,215 & $12.16 \%$ & 8,780 & $87.84 \%$ \\
\hline Grand total & & 3,812 & $9.08 \%$ & 38,149 & $90.92 \%$ \\
\hline
\end{tabular}

Despite the low percentage of the target group in the overall sample, results showed a significant increase in the population over each course term offered (Table 7).

To better understand how issues of affordability may interact with educational attainment, Table 8 provides details regarding which courses may have attracted target learners who held less than a 4-year degree. Course 6 was removed from the table as survey responses were unavailable for winter 2013. 
Table 8

Percentage of Learners in the Target Group Who Have Less than a 4-year Degree by Course

\begin{tabular}{llllll} 
& Course 1 & Course & Course & Course 4 & Course \\
& & 2 & 3 & & 5 \\
Fall 2012 & $22.41 \%$ & $12.60 \%$ & $14.42 \%$ & $26.99 \%$ & $9.50 \%$ \\
Winter & $34.64 \%$ & $16.47 \%$ & $18.48 \%$ & $35.12 \%$ & $12.72 \%$ \\
2013 & $\mathrm{z}=-3.54$, & $\mathrm{z}=-4.57$, & $\mathrm{z}=-6.67$, & $\mathrm{z}=-8.98$, & $\mathrm{z}=2.99$, \\
& $\mathrm{p}<0.01$ & $\mathrm{p}<0.01$ & $\mathrm{p}<0.01$ & $\mathrm{p}<0.01$ & $\mathrm{p}<0.01$ \\
\hline
\end{tabular}

As shown in Table 8, target learners with less than 4-year degrees had the highest enrollments in Courses 1 (Fantasy and Science Fiction) and 4 (Internet, History, Technology and Security). In addition to Humanities, these students are enrolling heavily into technology courses, which may suggest areas of future research. In fact, the increase in enrollment from fall 2012 to winter 2013 is statistically significant. Details of enrollment suggest that helping these populations may require access to courses that provide marketable skills.

\section{Engagement and Performance}

Log data of student activity in the course was used to analyze the participation, or engagement and performance between the two groups. These data included the number of times learners watched videos and completed assessments, forum engagement as well as the outcome earned in each course (no certificate, certificate, certificate of distinction). Overall, $48.88 \%$ of those that registered, including those not completing the surveys ( $\mathrm{N}=325,743 \mathrm{~N}_{\text {total }}=666,407$ ), performed some activity within the course (e.g., actually watched a video, up or downvoted a thread, viewed a thread or a forum, looked at course materials and/or conducted an assessment). Consistent with prior research on MOOC completion rates (Christensen, Steinmetz, Alcorn, Bennett, Woods, Emanuel, 2013; Ho, Reich, Nesterko, Seaton, Mullaney, Waldo \& Chuang, 2014), only $4.40 \%$ of all learners registered for these courses completed them and earned a certificate. Table 9 details the course completion results based on affordability. 
Table 9

Level of Completion Based on Affordability

\begin{tabular}{|c|c|c|c|c|}
\hline \multirow[t]{2}{*}{ Achievement level } & \multicolumn{2}{|c|}{$\begin{array}{l}\text { Target } \\
\text { (i.e., Cannot afford, } \mathrm{N}=3,812 \text { ) }\end{array}$} & \multicolumn{2}{|c|}{$\begin{array}{l}\text { Comparison } \\
\text { (i.e., Other, } N=38,149 \text { ) }\end{array}$} \\
\hline & Count & Percentage & Count & Percentage \\
\hline $\begin{array}{l}\text { Certificate with } \\
\text { distinction }\end{array}$ & 339 & $9.11 \%$ & 2,274 & $6.09 \%$ \\
\hline Certificate only & 716 & $19.24 \%$ & 13,645 & $36.58 \%$ \\
\hline $\begin{array}{l}\text { None (e.g., did not } \\
\text { complete) }\end{array}$ & 2,757 & $71.65 \%$ & 22,230 & $57.33 \%$ \\
\hline
\end{tabular}

There were no significant differences between the two groups' engagement in terms of watching videos, accessing course materials and/ or conducting assessments. However, as measured by the total count of forum activities (up vote, down vote, view thread and view forum), participation among the target population (94.65\%) was significantly less than the percentage of the comparison population $(96.68 \%, \mathrm{z}=6.5, \mathrm{p}<0.01)$. In addition, those in the comparison group had a higher percentage of course completion ( $36.58 \%$ vs. $19.24 \%, \mathrm{z}=21.07, \mathrm{p}<0.01$ ). Despite these findings, a higher percentage of the target group completed a course with a certificate of distinction than the comparison group (9.11\% vs. $6.10 \%, \mathrm{z}=7.18, \mathrm{p}<0.01)$.

\section{Summary of Results}

In summary, the demographics of learners from both groups were similar in coarse grain terms of gender (i.e., majority male), age (25-34 years old), and country of origin (i.e., majority U.S.), and are consistent with demographics reported in prior research (Christensen, Steinmetz, Alcorn, Bennett, Woods, Emanuel, 2013; Ho, Reich, Nesterko, Seaton, Mullaney, Waldo \& Chuang, 2014). The demographic results also showed that the second highest percentage of target and comparison learners was from India, which provides evidence of learners from developing regions (Ho, Reich, Nesterko, Seaton, Mullaney, Waldo \& Chuang, 2014).

In terms of educational achievement, results showed that a statistically significant portion of the target group ( $33.54 \%, \mathrm{~N}=1,271)$ had less than a four-year college degree in contrast to the comparison group (18.65\%, N=7,072). Similar findings have been reported in a more focused study (Dillahunt, Chen \& Teasley 2014). Target learners were also significantly more motivated to enroll in MOOCs than the comparison learners for all reasons except to supplement other courses. 
While learners in the target group primarily enrolled in Economics and Finance, those with less than a four-year degree enrolled at higher rates in the courses with content focused on basic technology. Consistent with the fact that they had higher levels of education, the comparison learners had higher enrollment in the more advanced technology course. Nevertheless, there was an indication that the percentage of learners indicating an inability to afford a formal education had increased with each offering of the course (e.g., 12\% increase in Course 1, 4\% increase in Courses 2 and 3, 8\% in Course 4 and 3\% in Course 5 per Table 8).

Finally, and perhaps the most interesting result, although comparison learners had a higher completion rate overall, target learners had a significantly higher rate of completing courses with certificates of distinction $(36.58 \%$ vs. $19.24 \%, z=21.07$, $\mathrm{p}<0.01$ ). This is despite the finding that participation among the target population was significantly less than the percentage of the comparison population. These results contribute insight into an unexplored MOOC population and additional insight into these learners' demographics, motivations, enrollment and performance; however, these findings raise additional questions and directions for future research.

\section{Discussion and Limitations}

The motivation behind this work was to understand the differences in demographics, motivations, course enrollment, and engagement and performance between learners who enrolled in a MOOC for reasons related to the affordability of traditional higher education as compared with learners who enrolled for reasons other than affordability. While the target learners could potentially reap the most economic benefit from taking these courses, the study findings show that this group only represents $9.08 \%$ of the surveyed population. A promising finding is that when these learners do complete a MOOC, they are more likely to earn a certificate with distinction than those who enrolled in the MOOC for reasons other than educational affordability. Understanding more detail about the motivations of these individuals is worth further investigation. For example, are these individuals primarily motivated for professional development? If so, are they specifically motivated to transition to new jobs, or to refresh their current skillset? Are the key differences in motivations between the target learners from the U.S. versus other regions related to geographic locations? These questions were beyond the scope of this initial exploration and fully understanding these findings will be aided by qualitative data focused on the nuances behind affordability.

\section{Study Limitations}

Perhaps the most significant limitation of this study is the potential for sampling bias inherent in opt-in surveys. Specifically, the survey method lends itself to a self-selection bias where learners choosing to respond to the pre-course surveys are usually more 
likely to be active course participants. In addition, those with the ability to respond to these surveys were more likely to respond-it is possible that those underrepresented populations which this study was designed to explore were the least likely to complete the surveys due to issues of affordability, accessibility and time. For example, certain regions may have intermittent Internet access or impose fees based on the amount of time spent online. Secondly, the reliability and accuracy of survey responses are always uncertain, and the issue of "affordability" is relative. For example, indicating, "I cannot afford to pursue a formal education" could mean that someone cannot afford to pursue a formal education financially, but it could also be interpreted as "I cannot afford to take time out of my schedule to pursue a formal education". It is also possible that some learners from the comparison group were not able to afford a formal education but they chose not to select this answer in the survey. Finally, the study data is limited to data from courses offered by a single U.S. university, though with a worldwide audience. Despite these limitations, the results of the analysis do offer an initial insight into an underrepresented and unexplored population of learners. These limitations alone provide implications for reaching underrepresented learners in the future.

\section{Future MOOC Research}

MOOCs are considered a means for democratizing education. An open question and challenge is to understand the feasibility of the MOOC model for opening up access to higher education and the potential to do so (McAuley, Stewart, Siemens \& Courmier, 2010). The demographic results of this study are consistent with prior research showing that MOOCs are primarily taken by well-educated males, 26 years and older, from developed regions and who are unlikely to encounter financial constraints for pursuing their education. Learners who have less formal education, women, older adults, individuals from developing regions, and those with financial constraints, are underrepresented in MOOCs.

As mentioned in the study limitations, leveraging the survey to understand demographics and motivations of MOOC learners presents sampling bias and difficulties in reaching targeted populations. To better understand the factors related to issues of affordability, future research should explore whether and how MOOC platforms can capture more detailed information about learners during their activity and engagement in the courses. For example, is there a way to determine if learners are accessing courses via broadband, mobile, dial-up or from public facilities such as libraries, Internet cafes (which may be more common in developing regions), or universities? How can statistical models be used to detect enrollment of learners from these populations? What features can be used to identify these learners and barriers they may face (e.g., IP address to identify location, engagement trends, the type of technology being used to access the MOOCs)? What interventions could reduce these barriers? 
Christensen, Steinmetz, and Alcorn (2013) describe a lack of technological access as the key reason poor people have not taken the opportunity to study online. Indeed research reveals that information and communication technologies have increased opportunities for higher education, although primarily for those individuals from affluent families from the Western Province (Liyanagunawardena, 2012). In an overview of the educational developments in open, distance, and technology-facilitated learning to reach world-wide populations deprived of education, Gulati found that new technologies have done little to help deprived groups gain access to educational opportunities (2008). Gulati's research has shown that these groups continue to be marginalized due to their lack of access to basic education and adequate learning resources. However, the rapid growth of mobile devices in developing countries may enhance the development of mobile learning to educate the masses (Gulati, 2008).

With worldwide penetration of the mobile-broadband subscriptions-almost 3 billion Internet users, two-thirds from the developing world and mobile-broadband uptake growing at double-digit rates by the end of 2014 (ITU, 2014) -access constraints may be declining. It is unclear, however, whether learners are leveraging mobile phones to access MOOC content. The results from this research suggest that financially constrained learners are finding ways to access these courses though these possibly represent the most motivated and the most affluent learners in certain regions. A better understanding of the methods in which learners access these courses could help to further understand these issues.

Although access is a concern, another issue could be a lack of awareness of the potential benefits MOOCs could offer. It is unclear how learners find out about MOOC courses and interesting to know whether sources differ from learners from the target and comparison groups. This could help to understand how information about the courses is currently being disseminated within these learner communities. Advertising MOOCs via billboards, radio and television, job placement offices, Internet cafes and libraries could help to raise awareness to the people who might benefit most from MOOCs. Although not discussed in the context of this study, it is also unclear whether and the extent in which English as the primary language of instruction in MOOCs presents access barriers to learners from developing and non-English speaking regions.

Finally, many unknowns still exist; including new pre-course survey questions could shed additional light on those learners that choose to complete the surveys. For example, requesting specific occupation information, current salary, place of degree attainment, and job type (e.g., full-time, part-time) could be beneficial. Understanding these factors could help to tease apart information about each cohort of learners and how these cohorts change over time. As mentioned earlier, exploring MOOC features to detect details such as methods of access and creating new models to predict when these learners engage could offer additional insight to ways to better meet the needs of these populations. 


\section{Conclusion}

The aim of this study was to address the question: How do the demographics, enrollment, personal motivations, performance and engagement of learners unable to afford a formal education compare or contrast to other learners? Results from six Coursera courses offered by the University of Michigan from fall 2012 through winter 2013 show that while learners who self-reported an inability to afford a formal education were majority males, primarily over 25 , they also

1. had a significant portion of learners with less than a four-year college degree than learners in the comparison group (33.54\% vs. $18.65 \%$, $\mathrm{z}=21.84$, $\mathrm{p}<0.01)$;

2. were generally more motivated to enroll in MOOCs than those in the comparison group due to issues of geographic isolation (five times more likely to select this motivation than comparison) and deciding if they wanted to take college/ university classes on the topic (twice as likely to select this motivation than comparison);

3. were significantly more likely to be awarded a certificate of achievement (9.11\% vs. $6.10 \%, z=7.18, p<0.01)$ than those in the comparison group.

The goal of this research was to explore underrepresented MOOC populations as a starting point to better understand how to open up access to higher education to economically constrained populations. Future work includes obtaining more qualitative data about targeted learners via interviews to better understand their MOOC experiences, whether their goals are to obtain certificates with distinction and why, and investigating models that help to predict targeted learners. Future work also includes updating surveys to obtain details about targeted learners such as income, place of degree attainment, and employment status.

\section{Acknowledgments}

The authors would like to thank the Bill and Melinda Gates Foundation for funding this work. Moreover, many thanks go to the invaluable feedback from our reviewers and from those in the USE Lab at the University of Michigan's School of Information. 


\section{References}

Christensen, G., Steinmetz, A., Alcorn, B., Bennett, A., Woods, D., Emanuel, E.

(November 6, 2013). The MOOC phenomenon: Who takes massive open online courses and why? Retrieved

from http:// papers.ssrn.com/ sol3/papers.cfm?abstract id=2350964

Clow, D. (2013). MOOCs and the funnel of participation. In Proc $3^{\text {rd }}$ international conference on learning analytics and knowledge (LAK '13), New York, pp 185189.

Dillahunt, T., Chen, B., \&Teasley, S. (2014). Model thinking: Demographics and performance of MOOC students unable to afford a formal education. Learning at Scale, Work in Progress, 2014.

Gulati, S. (2008). Technology-enhanced learning in developing nations: A review. The International Review of Research in Open and Distance Learning, 9(1), 1-16. Retrieved from http:// www.irrodl.org/index.php/irrodl/article/view/477

Ho, A. D., Reich, J ., Nesterko, S., Seaton, D. T., Mullaney, T., Waldo, J ., Chuang, I. (2014). HarvardX and MITx: The first year of open online courses (HarvardX and MITx Working Paper No. 1).

International Telecommunications Union (ITU). (April 2014). The world in 2014: ICT facts and figures. Retrieved from http:// www.itu.int/ en/ITUD/Statistics/Documents/ facts/ICTFactsFigures2014-e.pdf

Lewin, T. (2012, March 24). Instruction for masses knocks down campus walls. The New York Times. Retrieved from http:// goo.gl/ilPEc

Liyanagunawardena, T., Adams, A., Williams, S. (2013). MOOCs: A systematic study of the published literature 2008-2012. The International Review of Research in Open and Distance Learning, 14(3), 202-227. Retrieved from http:// goo.gl/VMOqt.

Liyanagunawardena, T. (2012). Information and communication technologies and distance education in Sri Lanka: A case study of two universities (PhD thesis). University of Reading. Retrieved from http:// centaur.reading.ac.uk/32337/

McAuley, A., Stewart B., Siemens G., Cormier D. (2010). The MOOC model for digital practice. Retrieved from http:// www.elearnspace.org/Articles/MOOC_Final.pdf

Pappano, L. (2012, November 2). "The Year of the MOOC.” The New York Times, ED26. Retrieved 
from http:// www.nytimes.com/2012/ 11/04/ education/ edlife/ massive-openonline-courses-are-multiplying-at-a-rapid-pace.html.

Vardi, M.Y., (2012). Will MOOCs destroy academia? Communications of the ACM, 55(11), 5.

Wulf, J ., Blohm, I., Brenner, W. \& Leimeister, J.M. (2014). Massive open online courses. In Business Information System and Engineering (BISE), Ersheinugsjahr/Year: 2014. Seiten/ Pages: Online First.

(c) Dillahunt, Wang, Teasley

\section{Athabasca University $\mathbf{A}$}

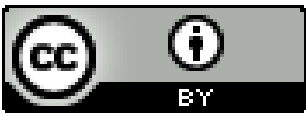

This work is licensed under a Creative Commons Attribution 4.0 International License. 